\title{
ESTRESSE: VIVÊNCIA PROFISSIONAL DE ENFERMEIRAS QUE ATUAM EM UTI NEONATAL
}

[Stress: nurses' professional experience in neonatal ICUS (Intensive Care U nit)]

[Tensión: vivencia profesional de enfermeras que actúan en unidad de vigilancia intensiva de

recién nacidos]

\author{
A lessandra M arin Santini* \\ Regina Gema Santini Costenaro** \\ Hilda M aria Freitas M edeiros*** \\ Cláudia Zaberlan****
}

RESUMO: Esta pesquisa descritiva exploratória objetivou identificar as fontes geradoras de estresse que acometem as enfermeiras que trabal ham em UTI N eonatal; reconhecer os fatores intrínsecos e extrínsecos que interferem nas condições biológicas e emocionais destas enfermeiras; saber se as condições de trabalho interferem no processo de cuidar. Participaram da pesquisa oito enfermeiras que responderam um questionário; destas $62 \%$ consideram-se estressadas, sendo o turno da tarde o mais estressante. As enfermeiras dedicam cinco horas semanais ao lazer e oito horas diárias ao sono, em média. Todas as participantes apresentaram sintomas de estresse, como perda de memória, anorexia, excesso de apetite, dificuldade de concentração, insônia, sonolência, cansaço e irritabilidade. Para 87\% das enfermeiras esses sintomas interferem no processo de cuidar. Os recém-nascidos chorosos, informar familiares do agravamento do paciente ou óbito, atividades administrativas, carência de recursos materiais e humanos contribuem para desencadear 0 estresse. Conclui-se que 0 ambiente de UTI neonatal é estressante. Sugere-se que os profissionais verbalizem seus sentimentos de angústia propiciando-Ihes alívio interior.

PALAVRAS-CHAVE: Estresse; Enfermagem; UTI Neonatal.

\footnotetext{
* Especialista em Enfermagem Cuidados Intensivos. Prof ${ }^{\circ}$ da Á rea de Ciências da Saúde do Centro Universitário Franciscano - UNIFRA. Santa M aria - RS. M embro do GEPECCE.

**D ra em Filosofia da Enfermagem. Prof ${ }^{\circ} A$ djunta na área de Ciências da Saúde do Centro Universitário Franciscano - UNIFRA. Enf ${ }^{\circ}$ A ssistencial da UTI RN-HUSM. Coordenadora do GEPECCE. ***M estranda do Programa de Pós-graduação em Enfermagem da UFRGS. Docente do Curso de Enfermagem do Centro Universitário Franciscano - UNIFRA. Santa M aria - RS. M embro do GEPECCE. ****M estre em Enfermagem. Prof ${ }^{\circ}$ da Á rea de Ciências da Saúde do Centro Universitário Franciscano - UNIFRA. Santa M aria - RS. M embro do GEPECCE.
}

\section{IINTRODUÇÃO}

0 ser humano começou a sofrer por estresse excessivo depois da Revolução Industrial, pois talvez o que a vida passou a exigir das pessoas nessas últimas décadas tenha sido muito maior do que o desenvolvimento da capacidade de adaptação das pessoas a este ambiente. I sto trouxe como resultado dificuldades em conciliar as necessidades adaptativas da vida social aos nossos recursos orgânicos, bem como nossas necessidades emocionais e espirituais.

A vivência de situações estressantes provoca uma síndrome com manifestações gerais o que poderia ajudar no processo de adaptação das pessoas ${ }^{(1)}$. Os conturbados tempos contemporâneos não são favoráveis ao equilíbrio e ao desenvolvimento pleno e saudável do corpo humano. $N$ este sentido, salienta-se que o estresse pode ser determinado pelo modo como nossa sociedade está organizada, pela industrial ização, pelo consumo, pela concorrência, pela exigência social a que somos submetidos, gerando condições estressantes de trabal ho. A ssim, 0 estresse pode ser um dos maiores fatores de risco para a vida e para a qualidade do viver. A pessoa estressada não se sente bem, produz menos e não se relaciona com as pessoas ao seu redor como gostaria ${ }^{(2)}$. Dentro deste contexto, está a enfermagem a qual é considerada uma das profissões mais estressantes devido às especificidades do trabal ho que realiza. O bservam-se dificuldades cada vez maiores desses profissionais para suportarem as cargas de trabal ho geralmente exaustivas, proporção inadequada de pacientes por profissional além de lidar com pacientes críticos, dor, sofrimento e morte.

A o atuarmos dentro de uma UTI, deparamo-nos com intensa atividade física e el evado grau de estresse emocional, conseqüência do contato permanente com alta tecnologia que mascara a relação pessoa a pessoa, com situações de vida ou morte, com a ansiedade familiar, além da própria expectativa quanto à sua eficiência no desempe- 
nho profissional ${ }^{(3)}$. Neste contexto, as enfermeiras assumem suas funções maternas e as tarefas domésticas, além de desempenhar várias atribuições no trabal ho, cujo esmero é cobrado pelas instituições de saúde ${ }^{(4)}$. A ssim as enfermeiras recebem uma demanda de funções e responsabilidades, trazendo implicações, pois são situações em que pessoas cuidando de outras pessoas e acabam por vivenciar determinadas situações de envolvimento af etivo sendo este inevitável.

Embasadas nestas idéias, preocupamo-nos com essa temática geradora de estresse no ambiente hospital ar, mais precisamente das enfermeiras que trabalham em uma U nidade de Terapia Intensiva (UTI) N eonatal de um H ospital Universitário local izado no interior do Rio G rande do Sul.

A ssim questionou-se nesta pesquisa: Como as enfermeiras administram as situações geradoras de estresse no ambiente de trabalho? 0 estresse tem interferido na produtividade profissional?

No intuito de elucidar nossas indagações, traçamos os seguintes objetivos:

1) Identificar as fontes geradoras de estresse que acometem as enfermei ras que trabalham em UTI N eonatal.

2) Reconhecer os fatores intrínsecos e extrínsecos que interferem nas condições biológicas e emocionais das enfermeiras.

3) Identificar se as condições de trabal ho geradoras de estresse interferem no processo de cuidar.

A s hipóteses que orientaram nosso estudo foram:

1) 0 ambiente de trabal ho em UTI N eonatal possui fatores geradores de estresse.

2) Os fatores intrínsecos e extrínsecos interferem nas condições biológicas e emocionais das enfermeiras.

3) As condições desfavoráveis de trabalho interferem no processo de cuidar.

\section{FUNDAMENTAÇÃO TEÓRICA}

\subsection{ESTRESSE}

Desde 1936 utiliza-se o termo "stress" (em português, estresse) ocasião em que Hans Seyle, utilizou pela primeira vez o termo em medicina. Desde então um grande número de pesquisas e publicações foram produzidas dentro desta linha de pensamento. 0 estresse é um conjunto de funções que os seres vivos desencadeiam quando enfrentam modificações do ambiente físico ou psicológico as quais são percebidas como ameaças à sua integridade. Com isso, o estresse é uma resposta de adaptação às modificações do meio, não sendo específica do organismo frente a uma exigência que Ihe é feita ${ }^{(5)}$. Pode ser designado como perturbações que podem causar distúrbios agudos ou crônicos no bem-estar das pessoas podendo surgir em função de estímulos físicos e ou emocionais ${ }^{(6)}$. 0 estresse é a reação que o corpo e a mente apresentam quando passam por uma situação difícil ou excitante que os motiva para uma ação. É um mecanismo normal necessário ao organismo, fazendo com que o ser humano fique mais atento e sensível diante de situações de perigo ou de dificuldade.

0 estresse como uma reação de adaptação a qualquer demanda feita a uma pessoa requer um reajuste para estabelecer o equilíbrio normal das funções orgânicas e psíquicas ${ }^{(7)}$. A todo instante estamos fazendo movimentos de adaptação, ou seja, tentativas de nos ajustarmos às mais diferentes exigências e situações. A s reações de estresse resultam dos esforços de adaptação.

A natureza do agente estressor é variável, ou seja, um evento que produzirá estresse em uma pessoa poderá ser neutro para outra. A meta desejada é a adaptação ou ajustamento à mudança, assim o estresse é como um estabilizador interno que nos al erta sobre o perigo dos excessos e os sintomas indicam que o corpo necessita de cuidados. N este processo a adaptação seria um aspecto constante requerendo um comportamento adequado de modo que a pessoa esteja melhor compatibilizada com 0 ambiente ${ }^{(8)}$. Deste modo, a adaptação é um processo individual em que cada pessoa tem diferentes níveis de capacidade para enfrentar ou responder.

\subsection{FASES DO ESTRESSE}

Quando nosso cérebro interpreta alguma situação como ameaçadora (estressante), todo nosso organismo passa a desenvolver uma série de al terações que em seu conjunto é denominada de Síndrome G eral de Adaptação. Esta consiste de três fases: R eação deA larme, Fase de Resistência e Fase de Exaustão. Não é necessário que a fase se desenvolva até 0 final para que haja o estresse e evidentemente só nas situações mais graves que se atinge a ultima fase, a de exaustão ${ }^{(5)}$.

$\mathrm{N}$ a primeira etapa dessa situação ocorre a $\mathrm{F}$ ase de Reação de Alarme, quando todas as respostas corporais entram em estado de prontidão geral. É um estado de al erta geral, como se fosse um susto. Desaparecendo os agentes estressores, todas essas al terações tendem a se interromper e regredir, mas se por al guma razão, o organismo continuar submetido ao fator gerador de estresse, é obrigado a manter seu esforço de adaptação. No entanto, se 0 agente do estresse for potente ou prolongado, poderá haver, como conseqüência uma maior predisposição a doença ${ }^{(5)}$.

$\mathrm{N}$ a medida em que o organismo se prepara para enfrentar uma situação estressante e que necessita se adaptar, acaba perdendo o equilíbrio interno ${ }^{(2,5)}$. A reação de alarme é defensiva e antiinflamatória, mas auto-limitada, pois é impossível para o fígado continuar em estado de alarme (resul taria em morte), então a pessoa passa para o segundo estágio que é o de resistência.

Se os agentes estressores não desaparecem, 0 organismo é obrigado a manter seu esforço de adaptação e uma nova fase acontecerá. Trata-se da Fase de Adaptação ou Resistência, em que o corpo que já está cansado, passa a 
ficar desgastado pel o grande consumo de energia que utiliza. Podem ocorrer dores de cabeça, gripes, resfriados, dentre outros. A pessoa nesta fase encontra dificuldades de concentração e memória, ocorrendo decréscimo na produtividade $^{(2,5)}$. Durante este estágio ocorre adaptação ao estressor nocivo, mas se a exposição ao estressor é prolongada, a exaustão inicia-se e a atividade endócrina aumenta, af etando principalmente o sistema circulatório, digestivo e imune ${ }^{(8)}$. A fase de exaustão pode ser iniciada quando a pessoa não consegue atingir uma certa harmonia capaz de equilibrar as forças internas ${ }^{(2)}$.

Se os estímulos estressores continuarem a agir, ou se tornarem crônicos e repetitivos, a resposta basicamente se mantém, podendo desencadear a $\mathrm{F}$ ase de Exaustão ou Esgotamento que é a mais perigosa, pois alguns sintomas da primeira fase aparecem, mas mais agravados, podendo haver um mai or comprometimento físico em forma de doenças. A exaustão causa esgotamento generalizado e baixam as defesas do organismo e seus si stemas articulados ${ }^{(2,5)}$.

\section{3 ÍNDICES DE ESTRESSE}

O estresse é a atitude biológica necessária para a adaptação do indivíduo a uma nova situação devendo ser considerado uma ocorrência natural na vida das pessoas. Os principais órgãos alvos de estresse são 0 aparelho digestivo, a coluna vertebral, pele, sistema respiratório, sistema cardiovascular, potência reprodutivo-sexual e sistema imunológico ${ }^{(9)}$.

Os sintomas são variados e podem ser observados com facilidade. Cada pessoa tende a desenvolver um padrão de comportamento característico do estresse o que caracteriza que o organismo está em desequilíbrio. Esta situação de desequilíbrio, persistindo, gera a doença ou somatiza no corpo através da preocupação ou do sentimento descontrolado de tristeza, mel ancolia, perda de algo, ou outra situação que gere um descontrole emocional ou psicológico.

Este estresse crônico a que nos referimos, produz desequilíbrios hormonais que determinam aumento de pressão sangüínea, prejudica os rins, desgaste nas paredes arteriais, deficiência coronariana, deficiência cardíaca, dentre outros ${ }^{(1)}$

Citam-se como alguns indicadores de estresse: Irritabilidade geral, hiper excitação ou depressão; sial osquiese; fadiga, perda de interesse; ansiedade, impaciência; gastral gia, distúrbios gástricos e intestinais (diarréia, vômitos); irregularidade no ciclo menstrual; anorexia ou polifagia; pal pitações cardíacas; instabilidade emocional; incapacidade de concentração; fraqueza ou torpor; tensão, tremores, tiques nervosos; insônia; tensão muscular, enxaqueca; lombargia, entre outros ${ }^{(8)}$.

\subsection{SÍNDROME DE BURNOUT}

O termo Burnouté uma composição de burn = queima e out = exterior, sugerindo assi $m$ que a pessoa com esse tipo de estresse apresenta problemas físicos e emocionais, passando a apresentar um comportamento agressivo e irritadiço. A ssim, a Síndrome de Burnout, na idéia de alguns autores ${ }^{(1,4,7,10)}$, está relacionada de maneira ef etiva com o estresse profissional, caracterizando-se por exaustão emocional, avaliação negativa de si mesmo, depressão e insensibilidade com relação a quase tudo e todos. Essa síndrome se refere a um tipo de estresse ocupacional e institucional com predileção para profissionais que mantêm uma relação constante e direta com outras pessoas, principalmente quando esta atividade é consi derada de ajuda como é o caso dos profissionais enfermeiros. Esta tensão emocional crônica gerada a partir do contato di reto, excessi vo e estressante com o trabalho, faz com que a pessoa perca o interesse em sua relação com o trabal ho e, assim, as coisas deixam de ter importância e qualquer esforço pessoal parece inútil. U m dos fatores associados ao desenvolvimento da Síndrome de Burnout está a pouca autonomia no desempenho profissional, problemas de relacionamento com chefia, colegas ou paciente.

Um dos primeiros princípios para o controle do estresse, pode ser gerenciado através de meios que auxiliem a reconhecer que as frustrações e tensões quotidianas são inevitáveis em nossa vida ${ }^{(10)}$. A s situações que causam estresse para uma pessoa não representam necessariamente um problema para outras. Há quem sinta bastante desconforto trabalhando sob pressão enquanto outros se tornam muito mais produtivos.

Para controlar o estresse é preciso manter uma qualidade de vida favorável a fim de preservar a saúde e a felicidade. $M$ anter uma alimentação saudável auxilia na preservação das reservas de energia no organismo uma vez que o corpo estressado consome muita energia.

Preservar o contato com amigos e familiares é importante, pois além de favorecer a socialização, mantém o contato com outras pessoas o que permite a troca de afetos. 0 controle do nível de estresse é importante porque assim a pessoa pode controlar a sua existência, possibilitando que o indivíduo desempenhe suas atividades com tranqüilidade e no máximo de suas funções, sem os efeitos colaterais, como problemas cardiovasculares, musculares e emocionais ${ }^{\left({ }^{10)}\right.}$. Na verdade, 0 estresse afeta a vida pessoal, assim como o desempenho profissional. Cabe a pessoa controlar o seu nível de tensão a fim de ter o domínio sobre o seu corpo e a sua mente.

\section{METODOLOGIA}

A presente pesquisa descritiva exploratória pertence à linha de pesquisa Cuidando e confortando em Enfermagem, a qual está inserida no Grupo de E studos e Pesqui- 
sas em Enfermagem: Cuidando, Confortando e Educando GEPECE.

A pesquisa descritiva exploratória busca conhecer as diversas situações e relações que ocorrem na vida social, política, econômica e demais aspectos do comportamento humano, tanto do indivíduo como de grupos e comunidades mais complexas ${ }^{(11,12)}$. A pesquisa descritiva também se desenvolve principal mente nas ciências humanas e sociais com o objetivo de conhecer situações, atitudes ou costumes predominantes através de descrições detal hadas, seja de pessoas, objetos ou atividades ${ }^{(13)}$.

Fizeram parte da amostra oito enfermeiras que atuam na Unidade de Terapia Intensiva N eonatal de um Hospital Universitário localizado numa cidade no interior do Rio Grande do Sul. Os dados foram coletados através de um questionário, sendo que a primeira questão abordou dados pessoais dos respondentes relacionado ao turno de trabaIho e tempo de atuação na enfermagem. $N$ as demais questões foram enfatizadas a temática em estudo de forma objetiva e subjetiva.

A análise dos dados foi feita pelo método estatístico e por categorização, ou seja, foram agrupadas as idéias que mais se repeti ram e posteriormente foram discutidas e comparadas à literatura. Com relação ao aspecto ético, foi seguida a R esolução 196/96 que descreve a ética na pesquisa com seres humanos ${ }^{(14)}$.

\section{APRESENTAÇÃO E DISCUSSÃO DOS DADOS}

Inicialmente temos a análise do instrumento de coleta de dados sobre as fontes geradoras de estresse que acometem as enfermeiras da UTI neonatal. D as entrevistadas $100 \%$ são do sexo feminino. Destas, 37,5\% possuem de 5 a 10 anos de atuação, $25 \%$ de 11 a 15 anos, 25\% de 16 a 20 anos e $12,5 \%$ possuem de 21 a 25 anos de atuação em UTI neonatal. Com relação ao turno de trabal ho, cinco (5) pertencem ao diurno e três ( 3 ) ao noturno.

Por ser considerado a UTI um ambiente fechado, com presença de muitos ruídos e por cuidar de R N em estado grave, pode-se considerar que seja um ambiente gerador de estresse. 0 fato de cinco enfermeiras, ou seja, $62,5 \%$ trabal harem nesta UTI por mais de 10 anos, já é um indício de que as mesmas podem apresentar sinais de estresse, sendo que estas também estão atreladas às turbulências do cotidiano extra profissional, além do que muitas vezes os profissionais da saúde possuem outro vinculo empregatício. Foi constatado neste estudo que $50 \%$ das respondentes desempenham outra atividade profissional.

Sabemos que o trabalho tem um papel fundamental na vida das pessoas permitindo a construção de identidade, da subjetividade e integração na vida social, mas como constatamos, estas enfermeiras enfrentam dupla jornada de trabal ho e esse ritmo frenético de atividades exige demasiadamente do corpo visto que até a possibilidade de adoecer passou a ser uma ameaça potencial ao sucesso pessoal e profissional. Viver implica mudanças, frustrações e problemas, exigindo uma adaptação constante do organismo, além disso, o estresse causa respostas diferentes sendo que uma pessoa pode viver um acontecimento devastador e o mesmo acontecimento para outra pode ser uma oportunidade de desenvolvimento ${ }^{(10)}$.

A o verbal izarem suas opiniões a respeito de se considerarem pessoas estressadas, observamos que $62 \%$ admitem que às vezes se sentem estressadas ao desempenhar suas atividades na UTI neonatal.

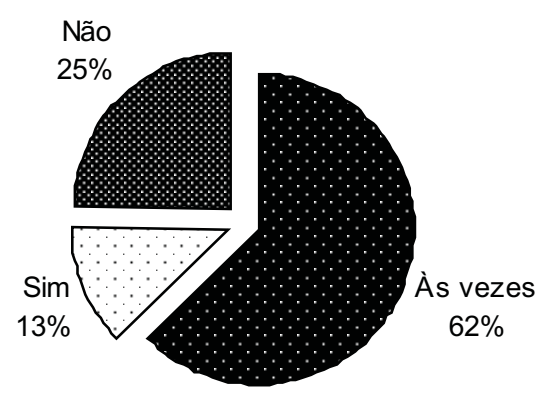

Figura 1 - O pinião das enfermei ras quanto ao seu nível de estresse, Santa M aria, 2003

0 tipo de desgaste físico e emocional que as enfermeiras estão submetidas com freqüência no ambiente de trabal ho em UTI neonatal são fatores significativos na determinação de transtornos relacionados ao estresse.

Por vezes tentamos ser absolutamente profissionais e acabamos nos esquecendo que também sofremos as ações contínuas de agentes estressores o que nos leva a nos descompensar quando menos esperamos ${ }^{(15)}$.

$\mathrm{Na}$ quarta questão, elaboramos a pergunta com relação ao turno de trabalho que é considerado mais estressante. Percebeu-se que no turno da tarde, 0 índice de estresse superam os outros turnos segundo as respondentes.

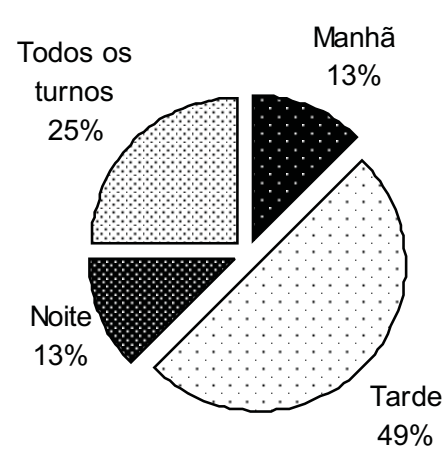

Figura 2 - Turno de trabal ho mais estressante, Santa M aria, 2003

A enfermagem é uma profissão considerada como potencial mente estressante baseada na citação de Cooper \& M itchell de 1988, quando a enfermagem foi classificada 
pela Health Education Authority como a quarta profissão mais estressante no setor público. Complementa a idéia dizendo que o enfermeiro encontra-se sob um estado constante de estresse decorrente do tipo de trabalho que executa, das condições ambientais do trabal ho, da fal ta de qualidade e das insuficiências próprias dos outros recursos humanos envolvidos nas equipes de saúde ${ }^{(16)}$.

Das enfermeiras entrevistadas, $75 \%$ afirmaram que trabal ham seis (6) horas e $25 \% 12$ horas diárias dentro da UTI RN. Estes resultados correspondem respectivamente ao contrato de trabal ho de 30 horas semanais das enfermeiras que atuam seis (6) horas diárias e a dupla jornada de trabal ho em que o menor grupo está envolvido.

Constatamos também, que $50 \%$ destas enfermeiras dedicam até 5 horas semanais ao lazer ou à prática de al guma atividade física, conforme verificamos na figura a seguir:

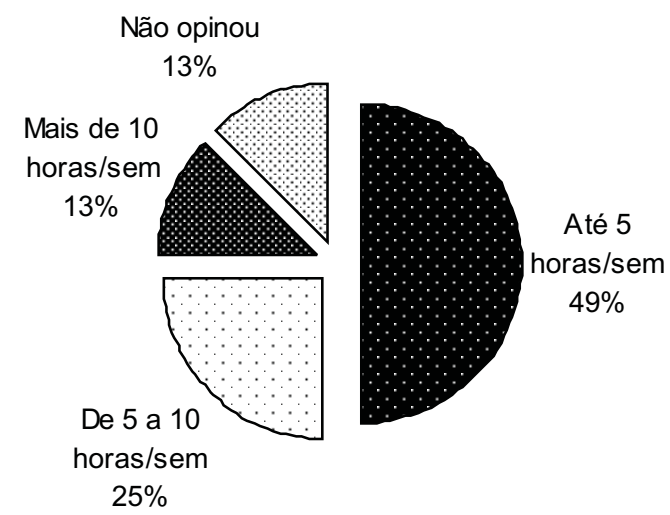

Figura 3 - Tempo semanal dedicado ao lazer ou a prática de atividade física, Santa M aria, 2003

A s enfermeiras rel atam que a qualidade de vida está mudando, pois possuem cada vez mais obrigações profissionais e conseqüentemente menos tempo para 0 enriquecimento pessoal. 0 tempo disponível para se alimentar reduziu e assim ingerem os al imentos mais rapi damente, dormem menos, o tempo que possuem é insuficiente para descansar e conhecer outras pessoas. E m conseqüência disto, as mesmas relatam que são afetados emocional mente principalmente por depressão e ansiedade.

Podemos dizer que nestas situações estressantes, 0 corpo fica tenso e o metabolismo acelera. A prática de exercícios físicos contribuiria para diminuir a tensão, tonificar os músculos e melhorar a oxigenação sanguínea e consequentemente prevenir doenças.

Constatou-se também que $62 \%$ das enfermeiras descansam oito horas diárias, o que é considerado uma boa média, já que o grande desgaste físico e emocional aliado a poucas horas de descanso, contribui para o surgimento do estresse.

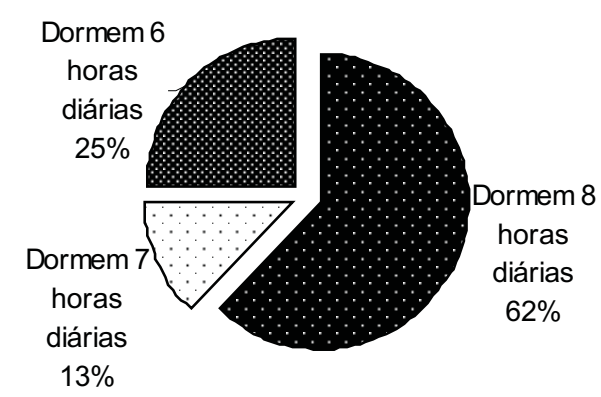

Figura 4 - M édia diária de horas de descanso, Santa M aria, 2003

A través de uma pesquisa sobre o sono constatou-se que dormir pouco favorece o surgimento de infecções, ou seja, a falta de sono debilita o sistema imunológico ${ }^{(17)}$. 0 sono também se manifesta de forma desordenada nas pessoas ansi osas e mais vul neráveis a estressores, piorando na medida que a idade avança e nos profissionais que permanecem mais tempo trabal hando à noite ${ }^{(4)}$.

A o perguntarmos às enfermei ras se já haviam sentido a necessidade de procurar por al gum apoio psicológico, constatamos que $49 \%$ das respondentes já demonstraram interesse em utilizar esse serviço.

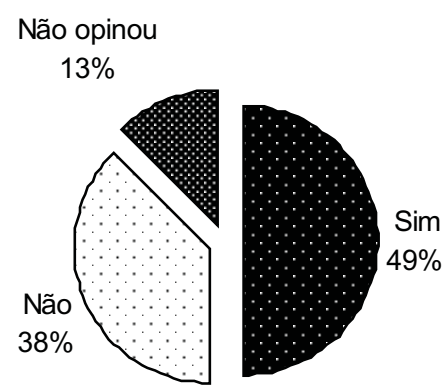

Figura 5 - Interesse em procurar apoio psicológico, Santa M aria, 2003

Grande parte dos casos de descompensação emocional de enfermeiros a esse estresse contínuo causado pela proximidade da condição doença, pelos ambientes tóxicos que as instituições de saúde encerram com sua fal ta de recursos humanos e materiais adequados e pela falta de suporte psicológico a esses profissionais ${ }^{(15)}$. A lém do paciente, 0 enfermeiro tem sob sua responsabilidade a equipe de enfermagem que precisa ser equilibrada, ter base e preparo psicológico para desenvolver um bom plano de cuidado (18).

Embora o local de trabalho manifestado pelas enfermeiras seja estressante, se fosse of erecida a oportunidade de troca, somente uma enfermeira gostaria de trabal har em outro setor. 
Sobre o sentimento de impotência das enfermeiras frente aos vários problemas enfrentados dentro da UTI neonatal, observamos que a maioria revel ou sentir-se impotente em diversos momentos e situações de conflito.

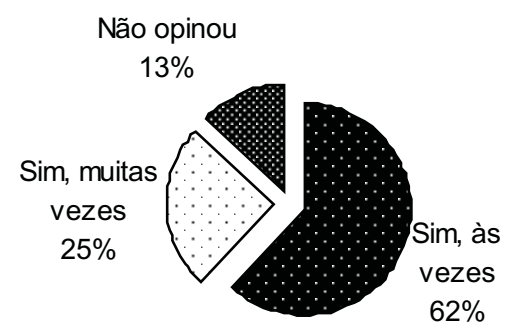

Figura 6 - Sentimento de impotência das enfermeiras na UTI neonatal, Santa M aria, 2003

No decorrer da assistência ao doente crítico, o envolvimento afetivo da enfermeira com o paciente de UTI acaba se tornando inevitável, o que a leva a compartilhar dos sucessos e fracassos do tratamento. N estas situações os enfermeiros vivenciam sentimentos de impotência quando a gravidade do quadro clínico impede a melhora do paciente ${ }^{(19)}$.

Q uando solicitado para assinal arem os possíveis sintomas indicadores de estresse, $100 \%$ das enfermei ras referiram algum sintoma. Os sintomas que mais prevaleceram foram:

Tabela 1 - Sintomas mais freqüentes revel ados pelas enfermeiras, Santa M aria, 2003

\begin{tabular}{lcc}
\hline Sintomas & Freqüência & $\%$ \\
\hline Dificuldade de concentração & & \\
e perda de memória & 08 & 24 \\
Perda ou excesso de apetite & 05 & 14 \\
Cansaço constante e irritabilidade & 05 & 14 \\
Desmotivação & 04 & 12 \\
Problemas gastrointestinais & 03 & 09 \\
Cefaléias e enxaquecas & 03 & 09 \\
Insônia ou sono exagerado & 02 & 06 \\
Perda da criatividade & 01 & 03 \\
Perda de interesse sexual & 01 & 03 \\
Baixa das defesas orgânicas & & \\
e psíquicas & 01 & 03 \\
Outros & 01 & 03 \\
\hline Total & 34 & 100 \\
\hline
\end{tabular}

Os sintomas que foram assinalados pelas enfermeiras são formas do corpo avisar que não está com o funcionamento perfeito de todas as suas funções. M uitos tratam 0 estresse como uma dor psicológica, que não necessita de cura ou tratamento, porém, vários tipos de manifestações com forte carga emocional levam a problemas graves.

Diariamente, nos defrontamos com momentos de dificuldades que podem resultar em uma ameaça para a manutenção e o equilíbrio de nossa vida. 0 estresse pode se acumular de tal forma que a pessoa simplesmente não consegue mais lidar com o que está acontecendo e adoece (20).

A o serem questionadas se os sintomas citados anteriormente interferem no processo de cuidar dos $\mathrm{RN} \mathrm{s}$ em UTI, sete enfermeiras, responderam que sim e uma não opinou.

0 bem estar do cuidador é uma condição essencial para realizar um cuidado com qualidade que assume importância vital quando este cuidado é prestado a um recémnascido, pois este é totalmente dependente dos profissionais responsáveis por sua assistência (4).

Para resultar na qualidade da assistência ao paciente é necessário envolvimento e dedicação do profissional responsável por ele. Quando nos referimos a cuidar de RNs, o comprometimento deve ser redobrado. Este cuidado integral está intimamente atrelado ao bem estar dos profissionais que cuidam dele ${ }^{(4)}$. Devemos estar sempre em busca da própria integridade, de nosso bem-estar, pois estes são considerados atributos essenciais aos profissionais do cuidado. A s enfermei ras e demais profissionais da área da saúde que atuam em unidade neonatal, necessitam estar em condições de integridade física e mental para poder oferecer atendimento pleno às demandas apresentadas pelos recémnascidos. I sto requer que estejam com adequada integração entre corpo e mente.

0 fator mais significativo gerador de estresse entre as enfermei ras quando estas estão em contato com RN s é 0 choro excessivo de acordo com a tabela 2.

Tabela 2 - Fatores geradores de estresse em enfermeiras relacionados ao contato com RN da UTI do estudo, Santa M aria, 2003

\begin{tabular}{lcc}
\hline \multicolumn{1}{c}{ Fatores } & Freqüência & $\%$ \\
\hline Cuidar de recém-nascidos & & \\
que choram muito & 04 & 66 \\
Ver recém-nascidos com dor & 01 & 17 \\
A guardar uma internação & 01 & 17 \\
\hline \multicolumn{1}{c}{ Total } & 06 & 100 \\
\hline
\end{tabular}

0 choro é a linguagem do RN sendo também a expressão mais comum indicadora de sofrimento físico ou psicológico. Esse pode ser a principal forma de comunicação do RN pois é através dele que podemos observar 0 sentimento individualizado, como tristeza, angústia, fome, sede, frio, calor, medo ou dor (21).

Quanto mais variável for o choro, menos suspeito se torna, mas quando se manifesta de uma única forma e 
com duração longa, o significado patológico precisa ser verificado (22). E mbasada neste autor, destacamos a importância da enfermagem na observação das formas de choro a fim de auxiliar a equipe médica nos diagnósticos que envolvem estes recém-nascidos.

Quando perguntamos quais seriam os fatores geradores de estresse enfrentados pelas enfermeiras quando estas entram em contato com os pais e familiares dos bebes internados na UTI, percebemos que os mais relatados foram quando precisam informar sobre a gravidade do estado do RN ou óbito e quando os familiares não demonstram interesse ou não visitam os RNs.

Tabela 3 - Fatores geradores de estresse em enfermeiras relacionados ao contato com os familiares dos RN da UTI do estudo, Santa M aria, 2003

\begin{tabular}{lcc}
\hline \multicolumn{1}{c}{ Fatores } & Freqüência & $\%$ \\
\hline $\begin{array}{l}\text { Notícia de agravamento ou morte } \\
\text { do RN }\end{array}$ & 06 & 43 \\
Não visitação ao RN por parte dos & 05 & 36 \\
familiares & 05 & \\
Resolução de conflitos entre os & 02 & 14 \\
familiares do R N & 01 & 07 \\
Orientações de alta hospitalar & 14 & 100 \\
\hline$\quad$ Total &
\end{tabular}

0 enfermeiro enfrenta em seu cotidiano profissional um ciclo envolvendo situações de vida e morte, tendo que respeitar e entender as formas peculiares de sentimentos e comportamentos dos pacientes e seus familiares ${ }^{(18)}$. Talvez aí esteja a grande dificuldade vivida na enfermagem, pois os enfermeiros al em de cuidarem dos $\mathrm{R} N \mathrm{~s}$ e seus familiares, também, resolvem os problemas relacionados a recursos humanos, recursos materiais dentre outros. Tudo isso gera um grande desgaste de energia, pois todo 0 andamento do setor esta sob sua responsabilidade.

Tabela 4 - Fatores geradores de estresse em enfermeiras relacionados às atividades administrativas da UTI RN do estudo, Santa M aria, 2003

\begin{tabular}{lcc}
\hline \multicolumn{1}{c}{ Fatores } & Freqüência & $\%$ \\
\hline Carência de recursos materiais & 07 & 32 \\
Falta de assiduidade e pontual idade & & \\
dos funcionários no serviço & 06 & 27 \\
Elaboração de escala mensal de & & \\
serviço & 06 & 27 \\
M anutenção de equipamentos & 02 & 09 \\
Elaboração de escala de distribuição & & \\
de leitos a cada turno & 01 & 05 \\
\hline \multicolumn{1}{c}{ Total } & 22 & 100 \\
\hline
\end{tabular}

Estas respostas parecem um tanto preocupante, uma vez que o RN não se comunica verbalmente, necessitando ser constantemente observado. A falta de assiduidade e pontualidade por parte dos funcionários pode deixar um viéz da falta de observação a alguns bebês. A trelado a isto, surge a carência de recursos materiais, que em situações de emergência, impedem que as atividades sejam realizadas com mais eficiência e eficácia.

Da mesma forma, a el aboração de escal a de serviço mensal parece um tanto complicada, pois os profissionais da enfermagem folgam apenas um ou dois finais de semana por mês, o que dificulta a realização desta distribuição principal mente em meses que possuem feriados ou outras datas comemorativas, além disso, a enfermeira tem que se preocupar em conciliar a escala de trabalho dos profissionais envolvidos em outra atividade ou que possuem dois empregos.

Os fatores ambientais da UTI que podem auxiliar na geração dos sintomas de estresse foram a luminosidade excessiva e presença constante de ruídos sonoros.

Tabela 5 - Fatores ambientais geradores de estresse em enfermeiras na UTI RN, Santa M aria, 2003

\begin{tabular}{lcc}
\hline \multicolumn{1}{c}{ Fatores } & Freqüência & $\%$ \\
\hline Ruídos sonoros contínuos & 06 & 40 \\
Luminosidade excessiva e & & \\
contínua & 04 & 27 \\
A Ita temperatura do ambiente & 03 & 20 \\
A mbiente fechado & 02 & 13 \\
\hline \multicolumn{1}{c}{ Total } & 15 & 100 \\
\hline
\end{tabular}

0 trabalho das pessoas pode ser influenciado pelas condições ambientais que são a luminosidade, o ruído e a sensação térmica ${ }^{(23)}$. A iluminação deve ser suficiente, constante e bem distribuída de modo a evitar a fadiga dos ol hos, decorrente das sucessivas acomodações em virtude das variações da intensidade da luz. Pesquisas revelam que os ruídos não provocam diminuição no desempenho profissional, mas a exposição prolongada a níveis el evados de ruído pode diminuir a acuidade auditiva ou perder a audição. A temperatura ambiental inadequada interfere na produtividade profissional.

0 principal fator, relacionado à equipe de enfermagem, que pode gerar estresse é a intensa atividade aliada a muitos dias de trabalho sem folga, causando grande desgaste físico. 
Tabela 6 - Fatores, relacionados à equipe de enfermagem, geradores de estresse em enfermeiras da UTI RN, Santa M aria, 2003

\begin{tabular}{lcc}
\hline \multicolumn{1}{c}{ Fatores } & Freqüência & $\%$ \\
\hline Jornada de trabalho exaustiva & 07 & 37 \\
Proporção inadequada de pacientes & & \\
por profissional & 04 & 21 \\
Remuneração inadequada & 03 & 16 \\
Carência de recursos humanos & 03 & 16 \\
Problemas de relacionamento & 02 & 10 \\
\hline \multicolumn{1}{c}{ Total } & 19 & 100 \\
\hline
\end{tabular}

Os profissionais de saúde geral mente enfrentam uma jornada de trabalho exaustiva aliada a um ambiente carregado de tensões e situações limítrofes. Desta forma, é importante discutir sobre as condições de vida do ser humano, principalmente do aspecto profissional, pois, deste depende muitas vezes a evolução de outros aspectos da pessoa, dentre os quais podemos citar o lazer, a al imentação, a vestimenta, enfim, a participação de si e de seus familiares na sociedade. Para tal, é importante que homens e mulheres sintam-se satisfeitos e realizados com as atividades que desenvolvem no ambiente de trabalho.

\section{CONSIDERAÇÕES FINAIS}

Sabe-se que o ambiente nas instituições de saúde é bastante doentio exigindo dos profissionais equilíbrio físico, mental ou emocional, sabedoria, disposição, dedicação e saúde atrelado a um bem estar para que estes possam exercer os cuidados de uma forma genuína. Sendo assim, confirma-se à hi pótese que o ambiente em UTI neonatal possui fatores geradores de estresse, sejam fatores intrínsecos ou extrínsecos do ser humano que interferem nas condições biológicas e emocionais das enfermei ras que trabal ham em UTI neonatal. Os achados desta pesquisa também confirmaram que as condições desfavoráveis de trabal ho interferem no processo de cuidar. Também se evidenciou que as principais fontes geradoras de estresse que acometem estas enfermeiras estão relacionadas ao contato com os RN s quando estes choram muito, pois esta situação gera um certo sentimento de impotência. 0 principal fator gerador de estresse relacionado ao contato com familiares dos $\mathrm{R} \mathrm{N} \mathrm{s}$ foi a notícia de agravamento ou morte do paciente e a não visitação por parte dos pais e familiares. Entre os fatores relacionados às atividades administrativas estão a carência de recursos materiais, a elaboração mensal de escala de serviço e a fal ta de assiduidade e pontualidade dos funcionários no serviço.

A ssim, para amenizar as situações de estresse sugerimos que a equipe de saúde, mais precisamente a enfermagem, exercite relações que oportunizem verbal izarem seus sentimentos, exporem suas angústias e exteriorizarem suas preocupações. Esta atividade alivia e acal enta o interior humano, aqui mais especificamente das enfermeiras, reduzindo, assim os fatores causadores de estresse e conseqüentemente um melhor atendimento aos pacientes internados e seus familiares.

ABSTRACT: This exploratory descriptive research aimed to identify the causes of stress that affect nurses working in neonatal intensive care units; to recognize the intrinsic and extrinsic factors that interfere in nurses' biological and emotional conditions; to know if work conditions interfere in the caring process. Eight nurses participated in the research, answering a questionnaire, and $62 \%$ considered themsel ves to be stressed, being the afternoon shift the most stressful. Nurses, as a rule, dedicate five hours a week to leisure and have eight hours of daily sleep. All the participants presented stress symptoms, such as: memory loss, anorexia, overeating, concentration difficulty, insomnia, sleepiness, tiredness and irritability. For $87 \%$ of them those symptoms interfere in the caring process. Tearful new borns, inform family about patient's worsening or death, administrative tasks, shortage of material and human resources contribute to stress. It can be concluded that the environment in neonatal intensive care units is stressful. It is suggested that these professionals verbal ize their anxiety in order to achieve self-relief.

\section{KEY WORDS: Stress; N ursing; N ewborn ICU.}

RESUMEN: Esta investigación exploratoria y descriptiva desea identificar las causas de la tensión que acomete las enfermeras que trabajan en las unidades de vigilancia intensiva de recién nacidos; reconocer los factores intrínsecos y extrínsecos que interfieren en las condiciones biológicas y emocionales de ellas; reconocer si las condiciones de trabajo interfieren en el proceso del cuidado. Ocho enfermeras participaron en la encuesta; $62 \%$ de ellas se consideraron estresadas, mientras creen que el turno de la tarde es el más estresante. L as enfermeras tienen cinco horas en la semana como tiempo libre y duermen diariamente ocho horas. Todas las partici pantes presentaron los síntomas de tensión, como: la pérdida de memoria, anorexia, exceso de apetito, dificultad de concentración, insomnio, sopor, cansancio e irritabilidad. Para $87 \%$ de ellas, esos síntomas interfieren en el proceso del cuidado. El recién nacido Iloroso, informar a la familia sobre el paciente que está empeorando o sobre su muerte, actividades administrativas, escasez de material y de recursos humanos contribuyen para causar la tensión. Sigue que la atmósfera de unidades de vigilancia intensiva de recién nacidos es estresante. Se sugiere que estas profesionales pongan en palabras sus angustias y sentimientos, para que al cancen alivio interior.

PALABRASCLAVE: Tensión; Enfermeras; UVI de recién 
nacidos.

\section{REFERÊNCIAS}

1. A ngerami-Camon VA, Chiattone HBC, Nicoletti ÊA . O D oente, a psicologia e o hospital. São Paulo: Pioneira; 1992.

2. Lipp MN, Novaes LE. Mitos e verdades sobre o stress. São Paulo: Contexto; 1996.

3. Costenaro RGS. A mbiente terapêutico de cuidado ao recém-nascido internado em UTI neonatal. Santa M aria: Palotti; 2001.

4. Hoga LAK. Causas de estresse e mecanismos de promoção do bemestar dos profissionais de enfermagem de U nidade N eonatal. A cta Paul Enferm 2002; 15(2): 18-25.

5. Selye H. Stress:a tensão da vida.São Paulo:IBRA SA; 1959.

6. Fiorelli J0. Psicologia para administradores: integrando teoria e prática. 2. ed. São Paulo: A tlas; 2001.

7. Simmons R. Estresse: esclarecendo suas dúvidas. São Paulo: Á gora; 2000.

8. B runner LS, Suddarth DS. Tratado de enfermagem médico-cirúrgica. Rio de Janeiro: Guanabara K oogan; 2000.

9. Deitos TFH, Gaspary JFP. M ito de Ulisses: estresse, câncer e imunidade. Santa M aria: K aza do Zé; 1997.

10. Rossi A M . A utocontrole: nova maneira de controlar o estresse. Rio de Janeiro: Rosa dos Tempos; 1991.

11. Lakatos EM, M arconi M A. M etodologia do trabalho científico: procedimentos básicos; pesquisa bibliográfica, projeto e relatório, publicações e trabalho científico. São Paulo: A tlas; 1987.

12. Ludke $M$, A ndré EDA. Pesquisa em educação: abordagens qualitativas. São Paulo: EPU; 1986.

13. Eco U. Como se faz uma tese em ciências humanas. Lisboa: Presença; 1988.

14. M inistério da Saúde (BR ). Conswlho Nacional de Saúde. Decreto no 93.933 de 14 de Janeiro de 1987. Bioética 1996; 4:15-25.

15. Sá A C. O cuidado do emocional em enfermagem. São Paulo: Robe; 2001.

16. Stacciarini JMR, Tróccoli BT. Estresse ocupacional, satisfação no trabalho e mal-estar físico e psicológico em enfermeiros. Nursing Rev Tecn Enferm 2000; (20):30-4.

17. M acagnan ], Costenaro RGS. Sono $x$ trabalho noturno. [TCC graduação]. Santa M aria: UNIFRA; 2000.

18. Flores F, Costenaro RGS. 0 enfrentamento da morte: uma questão pouco discutida pelos profissionais de saúde. [TCC graduação]. Santa M aria: UNIFRA; 2000

19. Padilha K G, K itahara PH, G onçalves CCS, Sanches A L C. O corrências iatrogênicas com medicação em Unidade de Terapia Intensiva: condutas adotadas e sentimentos expressos pelos enfermeiros. Rev Esc Enferm USP 2002; 36(1):50-7.

20. Simonton C, M atthews-Simonton S, Creighton JL. Com a vida de novo: uma abordagem de auto-ajuda para pacientes com câncer. São Paulo: Summus; 1987.

21. Costenaro RGS. A uto-conhecimento e educação: uma interação psicossomática. In: Vidor A, Seibert VA (organizadores) Natureza humana e educação. Frederico Westphalen: URI; 1998.

22. Gruspun H. Distúrbios psicossomáticos da criança: o corpo que chora. Rio de J aneiro: A theneu; 1988.

23. Chiavenato I. Recursos humanos. São Paulo: A tlas; 2000.

ENDEREC D DOSAUTORES:

Caixa Postal 288

Santa M aria - RS

97060-090

santini@bol.com.br

Cogitare Enferm 2005 set/dez; 10(3):14-22 